\title{
Orthodontic Treatment for Congenitally Missing Maxillary Lateral Incisors with Canine Substitution: A Case Report
}

ISSN: 2639-0531

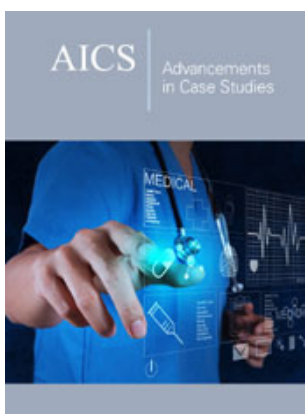

*Corresponding author: Tzu-Hsin Lee, Professor and clinical instructor, Department of Orthodontics, Changhua Christian Hospital, Taiwan, R.O.C

Submission: 侮June 20, 2019

Published: 㘹June 25, 2019

Volume 1 - Issue 5

How to cite this article: Jui Ann H, Tzu Hsin L. Orthodontic Treatment for Congenitally Missing Maxillary Lateral Incisors with Canine Substitution: A Case Report. Adv Case Stud.1(5). AICS.000525.2019. DOI: 10.31031/AICS.2019.01.000525

Copyright@ Jui Ann HSU, This article is distributed under the terms of the Creative Commons Attribution 4.0 International License, which permits unrestricted use and redistribution provided that the original author and source are credited.
Jui-Ann HSU ${ }^{1}$ and Tzu-Hsin LEE ${ }^{2 *}$

${ }^{1}$ Department of Orthodontics, China Medical University and Medical Center, Taiwan, R.O.C

${ }^{2}$ Department of Orthodontics, Changhua Christian Hospital, Taiwan, R.O.C

\begin{abstract}
This case report presented the orthodontic treatment for an 18-year-old female patient who has Class I malocclusion with bilateral missing maxillary lateral incisors, proclined lower incisors and slight convex profile. According to the profile of the patient, the space analysis of dentition and the color and shape of canine, these above factors favored canine substitution and lower first premolar extraction as our treatment plan. The anterior teeth esthetics was achieved by orthodontic space closure and rehabilitated by composite resin build-up. The patient was satisfied with the treatment outcome.
\end{abstract}

\section{Introduction}

Maxillary lateral incisor agenesis (MLIA) is a common dental anomaly. It has been reported that the prevalence rate was higher in Asians [1-3] and in females. The prevalence rates of congenital missing upper and lower lateral incisors were $2.7 \%$ and $4.8 \%$, respectively [4]. MLIA may be caused by multiple reasons, including infection, trauma, medication and a group of related syndromes (cleft lip \& cleft palate, ectodermal dysplasia and Down syndrome). Also, the mutation of MSX and PAX9 can also lead to dental agenesis [5].

Treatment plan can be divided into three categories: canine substitution, single-tooth implant and tooth supported restorations. Among which the least invasive option to achieve satisfying function and esthetics is canine substitution. Different approaches, such as prosthetic restoration, periodontal surgery which demand proper interaction of dental specialties may lead to predictable results. However, for a balanced dentition, optimal esthetics outcomes, occlusal function and the color and size of canine should be taken into consideration in the treatment plan.

\section{Case Report}

An 18-year-old female patient presented with a chief complaint of "many spaces over upper teeth and want to close all the space". The extra-oral examination showed that the chin deviated toward left side for $2 \mathrm{~mm}$. The nasolabial angle was slightly acute $\left(90^{\circ}\right)$. An intraoral examination revealed Angle Class I malocclusion with bilateral maxillary lateral incisors missing. The space analysis showed $10 \mathrm{~mm}$ of space in upper dentition and $1 \mathrm{~mm}$ space deficiency in lower dentition. Both upper and lower dental arch were symmetric ovoid shape (Figure 1). Cephalometric analysis indicated the facial pattern was skeletal class I malocclusion with proclined mandibular incisors as compared to norms (Figure 2); (Table 1).

\section{Treatment objectives}

Treatment objectives were addressed as:

a) Space closure with canine substitution and recontouring it into lateral incisor

b) Establish group function occlusion

c) Achieve straight profile by avoiding over-retraction of maxillary anterior teeth 


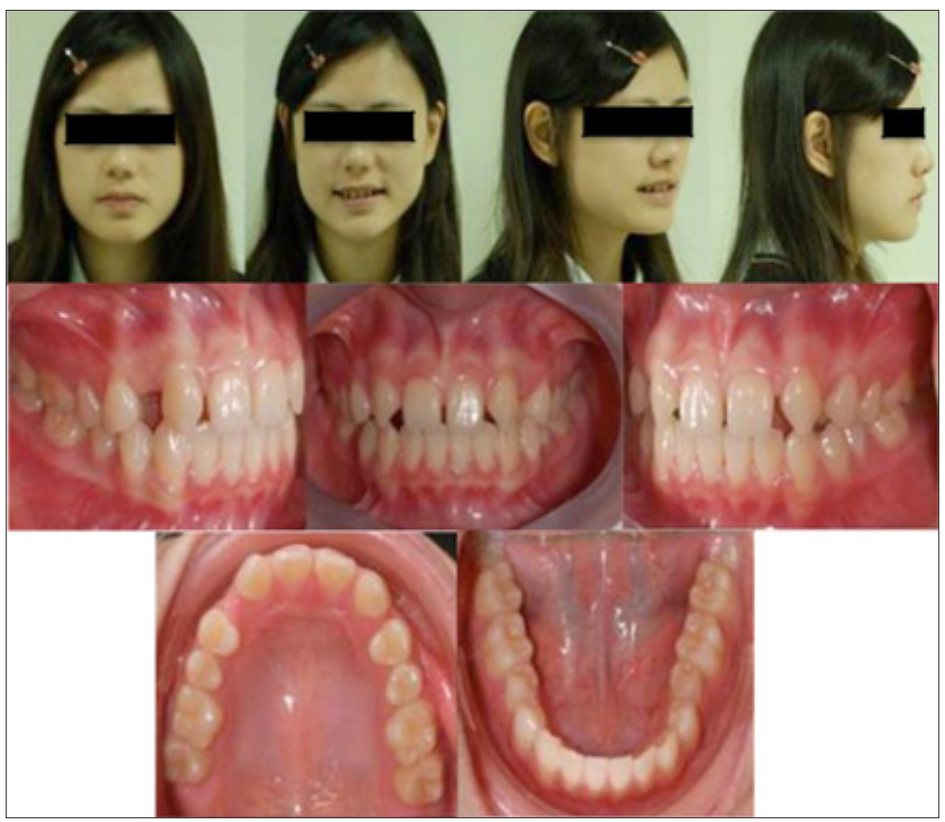

Figure 1: Before orthodontic treatment. Extraoral photos and intraoral photos.
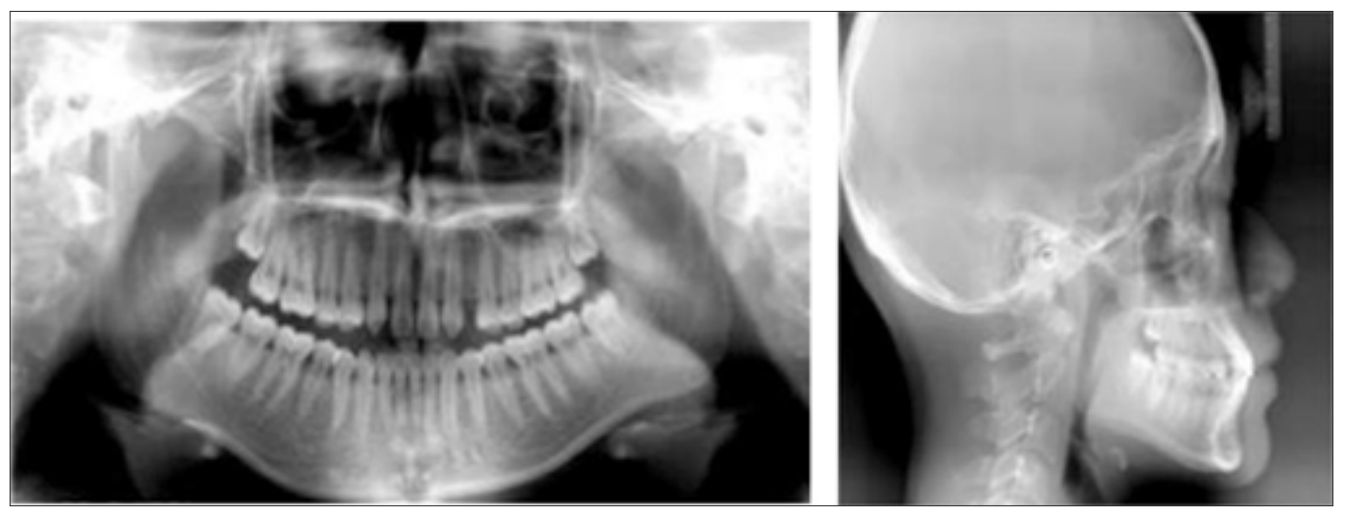

Figure 2: Initial panoramic and cephalometric radiograph.

Table 1: Cephalometric analysis.

\begin{tabular}{|c|c|c|c|}
\hline Skeletal & Norm & Initial & Final \\
\hline SNA & $82^{\circ}$ & $81^{\circ}$ & $70^{\circ}$ \\
\hline SNB & $80^{\circ}$ & $79^{\circ}$ & $2^{\circ}$ \\
\hline ANB & $2^{\circ}$ & $2 \mathrm{~mm}$ & $0 \mathrm{~mm}$ \\
\hline Nv-A & $0.4 \mathrm{~mm}$ & $4 \mathrm{~mm}$ & $2 \mathrm{~mm}$ \\
\hline Nv-Pog & $-4 \mathrm{~mm}$ & $22^{\circ}$ & $13^{\circ}$ \\
\hline Occl-SN & $14^{\circ}$ & $32^{\circ}$ & $35^{\circ}$ \\
\hline GoGn-SN & $32^{\circ}$ & $25^{\circ}$ & $26^{\circ}$ \\
\hline FMA & $31^{\circ} \pm 5^{\circ}$ & $-4 \mathrm{~mm}$ \\
\hline Wits & $-1.4 \pm 2.6$ & 1.954167 & 1.954167 \\
\hline UFH:LFH & 1.913194 & Initial & $108^{\circ}$ \\
\hline Dental & Norm & $5 \mathrm{~mm}$ & $22^{\circ}$ \\
\hline U1-SN & $104^{\circ}$ & $26^{\circ}$ & $5 \mathrm{~mm}$ \\
\hline U1-NA & $4 \mathrm{~mm}$ & $22^{\circ}$ & $21^{\circ}$ \\
\hline U1-NA & & & \\
\hline
\end{tabular}




\begin{tabular}{|c|c|c|c|}
\hline U1-L1 & $130^{\circ}$ & $120^{\circ}$ & $133^{\circ}$ \\
\hline L1-NB & $4 \mathrm{~mm}$ & $5 \mathrm{~mm}$ & $2 \mathrm{~mm}$ \\
\hline L1-NB & $25^{\circ}$ & $30^{\circ}$ & $21^{\circ}$ \\
\hline IMPA & $94^{\circ} \pm 6$ & $99^{\circ}$ & $90^{\circ}$ \\
\hline
\end{tabular}

\section{Treatment plans}

According to patient's chief complaint, she didn't want to have crowns or any other prosthesis restoration. Therefore, the treatment plans were:

A. Extraction of teeth \#34 and \#44

B. Maxillary space closure with canine substitution

C. Full mouth orthodontic treatment with fixed appliance
D. Recontour the canines with composite resin

Treatment Progress and Results

After extraction of bilateral lower first premolars, the initial leveling and alignment were performed, followed by loop mechanism for space closure. Intermaxillary elastics were used to achieve maxillary space closure. After closing all the space of both arches and detailing, canine recontouring was performed. The patient was satisfied with the treatment results after two years of orthodontic treatment (Figure 3-5).

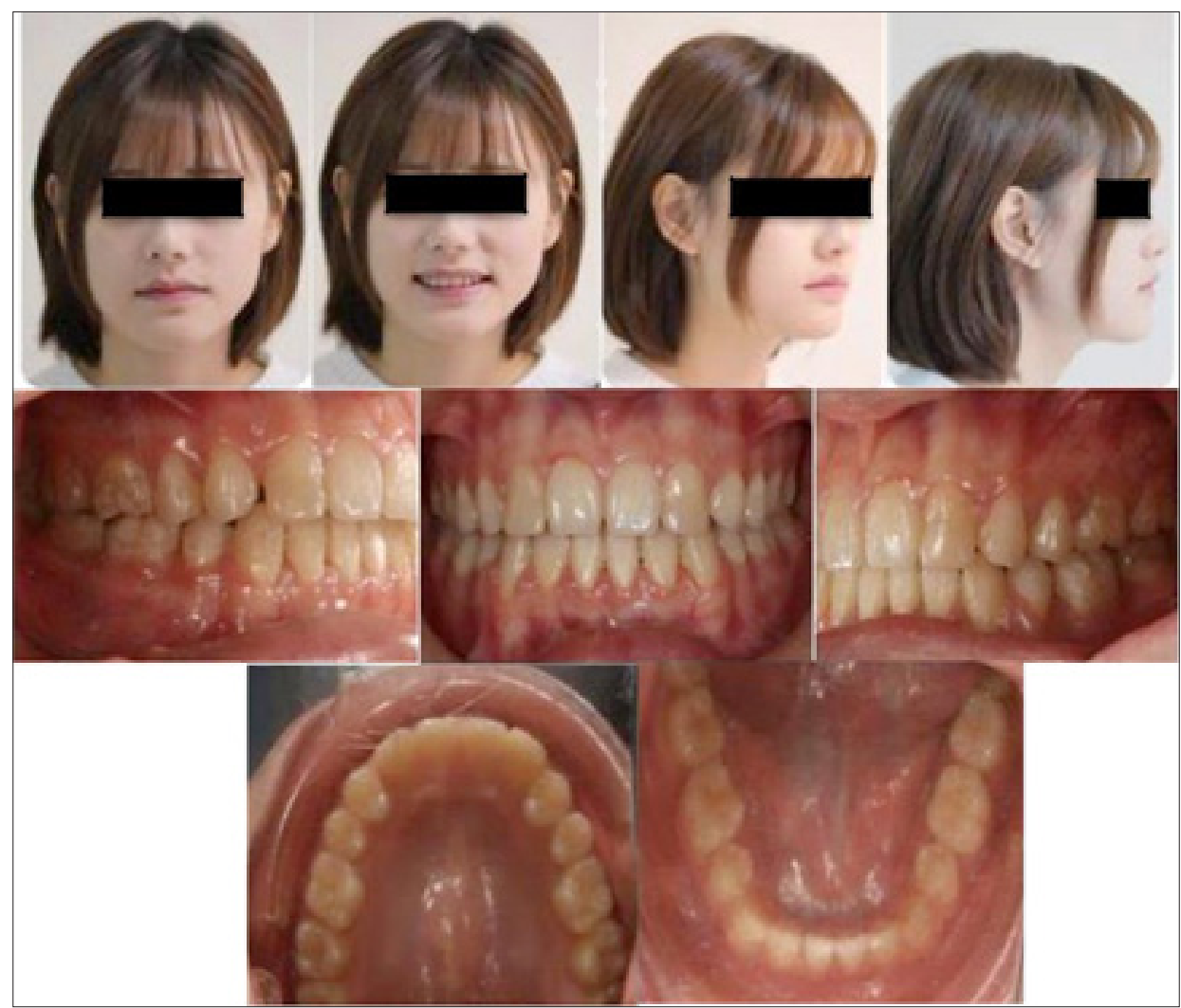

Figure 3: After orthodontic treatment. Extraoral photos and intraoral photos.
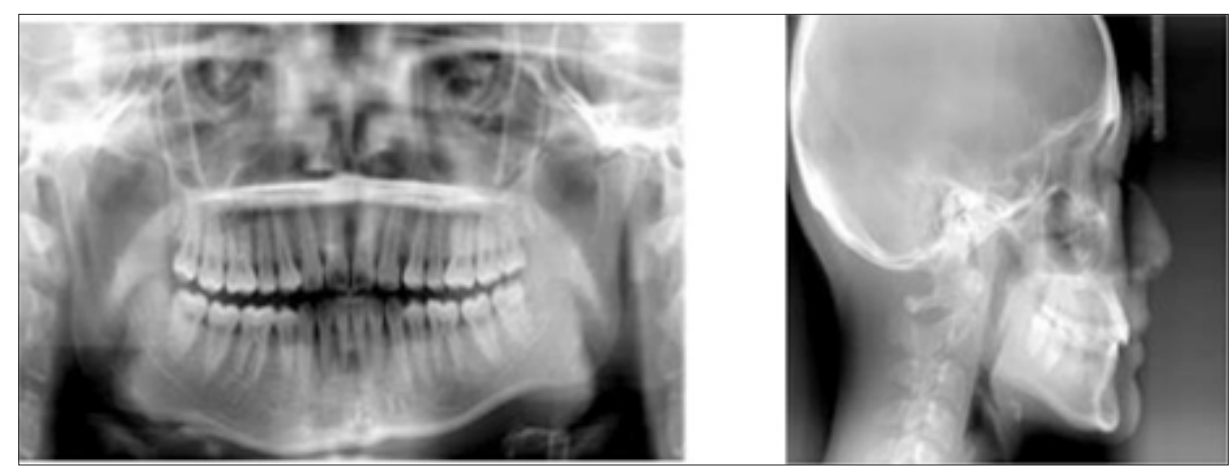

Figure 4: Post treatment panoramic and cephalometric radiograph. 


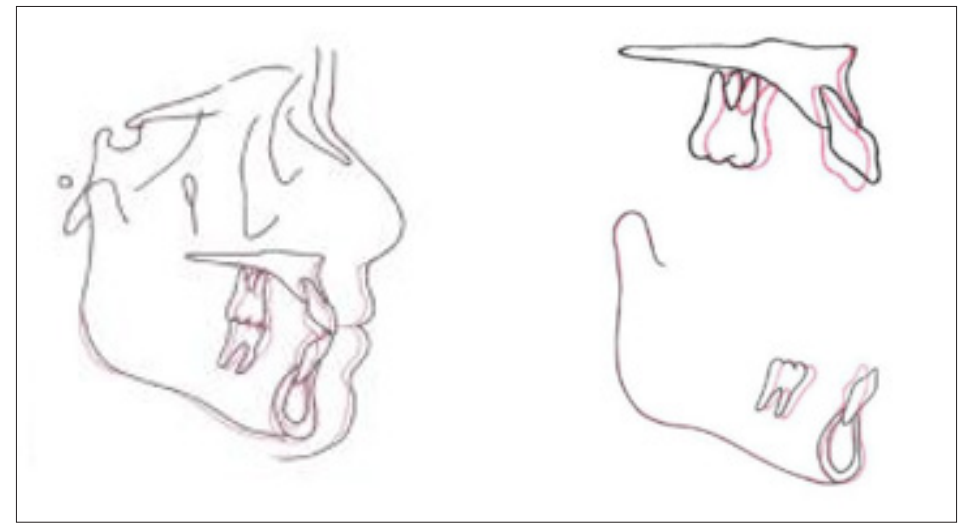

Figure 4: Cephalometric superimposition.

\section{Discussion}

Three treatment options for MLIA had been reported as followed: canine substitution, single-tooth implant and tooth supported restoration.

\section{Option 1: Canine Substitution}

Space closure and canine recontouring are important treatment options for the MLIA patient. A harmonious smile can be achieved by proper interaction with other dental specialties.

The indication for canine substitution includes the following [6]:

a. Angle Class II malocclusion with no crowding in the mandibular arch

b. Angle Class I malocclusion with sufficient crowding to necessitate mandibular extraction

c. Similar size as well as shape of canines and premolars

d. Balanced, straight or mild convex profile of the patient

According to Zachrisson et al. [7], there are six steps to properly achieve optimal space closure.

\section{A. Step 1: Space closure}

Sometimes extraction of lower two premolars is necessary, depending on the severity of crowding, dental protrusion, profile and growth pattern. We must notice that the mandibular arch form should not be expanded and should coordinate with the maxillary arch form.

\section{B. Step 2: Orthodontic finishing in the maxillary anterior} region

Due to the different sizes and shapes between lateral incisors and canines, the space between canine and first premolar after canine reduction should not be closed because it can be utilized as recontouring first premolar or increasing the width by rotating premolars. The torque control is another point. If the gingiva shows thin biotype, palatal root torque will be indicated by high torque braces or third-order bend. The torque control and angulation can be reevaluated by CBCT at the final stage.

\section{Step 3: Gingivoplasty}

Sometimes localized gingivectomies are required to level the gingival margins. A gingivectomy should be performed posttreatment and after repeated sessions of oral hygiene instruction. It is very important to motivate and educate patients to have proper oral hygiene, during, and after the orthodontic treatment, to maintain normal healthy periodontal tissues.

\section{Step 4: Esthetic restorations}

A balanced and attractive exposure of the upper front teeth is a component to esthetic smile. Transversally, Lombardi [8] proposed that the visible width of maxillary incisors and canine should follow the golden proportion and it is about 1.618 to 1 . Vertically, for the patients with MLIA their teeth are always shorter than normal people. To achieve the optimal width to length proportion, it is important to increase the length of central incisors and canine extruded for "high low high "gingival contours. As for first premolar, intrusion and a wider restoration is needed to build up a caninelike morphology. With regard to functional aspects, group function is indicated, followed by space closure.

\section{E. Step 5: Vital bleaching}

Usually, the color of canines is darker than the central incisors. Vital bleaching of canine may be required to minimize the color difference. Nocturnal use of $10 \%$ hydrogen peroxide gel in an Essix retainer is a preferred way. On the other hand, the prosthetic treatment should be finished after bleaching treatment.

F. Step 6: Occlusal finishing, final restorations and longterm stability the orthodontic treatment should aim to these points as below:

a. Do not over expansion of lower arch and maintain the initial arch form

b. Fixed retainer appliance is indicated in lower anterior teeth

c. To achieve lip competence after treatment

d. Treatment without CO-CR discrepancy.

e. Group function is better than pure canine protected occlusion 
Upper anterior teeth is potential to shift after orthodontic treatment. For the purpose of maintaining the space closed, it is suggested to use fixed retainers [9-10]. If composite recontouring is not satisfactory, veneers are indicated. After retention for 8-12months, a temporary prosthodontics can be installed. When a stable occlusal condition is confirmed, it is proper to insert the final ceramic restoration, followed by fixed retainer again.

\section{Treatment option 2. tooth-supported restorations}

There are three ways to establish the appropriate space: golden proportion, contralateral lateral incisor width and Bolton analysis. The restorations can be divided into three methods: (1) resinbonded fixed partial denture; (2) cantilever fixed partial denture; (3) conventional full-coverage fixed partial denture. The success rate depends on several factors: position, mobility, thickness, and translucency of the abutment teeth as well as the overall occlusion. And we should choose the appropriate prosthesis according to the patient's occlusion and oral condition.

\section{Treatment option 3. implant supported restorations}

The movement of canines can increase the width of osseous ridge [11]. Whatever the situation is, the implant can only be placed after the facial growth is completed. It is suggested to keep the space (around $1.5 \mathrm{~mm} \sim 2 \mathrm{~mm}$ ) between the head of the implant and the adjacent teeth to develop papilla [12]. The implant dimension should be estimated by the space of lateral incisor. On the other hand, the angulation of the root of adjacent tooth is another concern. For instance, a patient with Class III tendency requires maxillary incisors proclination. This will result in less convergent roots apex. Under such condition, alternative treatment will be needed [13].

\section{Conclusion}

Congenitally missing maxillary lateral incisor is one of the most common agenesis anomalies. Treatment plan can be divided into three categories: canine substitution, single-tooth implant and tooth supported restorations. We should determine the treatment plan based on patient 's profile, occlusion and chief complaint. In summary, this case report demonstrates that orthodontic treatment with canine substitution is a practical approach to treat lateral incisor agenesis. Meanwhile, canine recontouring performed after closing the lateral incisor space of upper dentition did achieve a satisfactory normal occlusion.

\section{References}

1. Robertsson S, Mohlin B (2000) The congenitally missing lateral incisor. A retrospective study of orthodontic space closure versus restorative treatment. Eur J Orthod 22(6): 697-710.

2. Fekonja A (2005) Hypodontia in orthodontically treated children. Eur J Orthod 27(5): 457-602.

3. Kavadia S, Papadiochou S, Papadiochos I, Zafiriadis L (2011) Agen-esis of maxillary lateral incisors A global overview of the clinical problem. Orthodontics (Chic) 2011 Winter 12(4): 296-317.

4. Fujita Y, Hidaka A, Nishida I, Morikawa K, Hashiguchi D, et al. (2009) Developmental anomalies of permanent lateral incisors in young patients. J Clin Padiatr Dent 33(3): 211-215.

5. Mostowska A (2003) Novel mutation in the paired box sequence of PAX9 gene in a sporadic form of oligodontia. Eur J Oral Sci 111(3): 272-276.

6. Kokich VO, Kinzer GA (2005) Managing congenitally missing lateral incisors. Part I: Canine substitution. J Esthet Restor Dent 17(1): 5-10.

7. Zachrisson BU, Rosa M, Sverker T (2011) Congenitally missing maxillary lateral incisors: canine substitution. Am J Orthod Dentofacial Orthop 139(4): 434-445.

8. Lombardi RE (1973) The principles of visual perception and their clinical application to denture esthetics. J Prosthet Dent 29(4): 358-382.

9. Camporsie M, Bassciti T, Marnelli A, Defaria E, Franchi L (2010) Maxillary dental anomalies in children with cleft lip and palate-A controled study. Int J Paediatr Dent 20(6): 442-450.

10. Stamateu J, Simons AL (1991) Agenesis of permanent lateral incisor: Distribution, number and sites. J Clin Padiatr Dent 15(4): 244-246.

11. Krassnig M, Fickl S (2011) Congenitally missing lateral incisors--a comparison between restorative, implant, and orthodontic approaches. Dent Clin North Am 55(2): 283-299.

12. Kokich VG (2004) Maxillary lateral incisor implants planning with the aid of orthodontics. J Oral Maxillofac Surg 62(9 Suppl 2): 48-56.

13. Kinzer GA, Kokich Jr VO (2005) Managing congenitally missing lateral incisors Part 3: single-tooth implants. J Esthet Restorat Dent 17(4): 202210.

For possible submissions Click below: 